\title{
Applying the Flipped Classroom Methodology in a First-Year Undergraduate Music Research Methods Course
}

\section{Carolyn Doi}

To cite this article: Carolyn Doi (2016) Applying the Flipped Classroom Methodology in a FirstYear Undergraduate Music Research Methods Course, Music Reference Services Quarterly, 19:2, 114-135, DOI: 10.1080/10588167.2016.1167427

To link to this article: https://doi.org/10.1080/10588167.2016.1167427

\section{Published online: 21 May 2016.}

Submit your article to this journal ¿

Џ Article views: 636

Q View related articles 5

View Crossmark data [ד

Citing articles: 2 View citing articles $\square$ 


\title{
Applying the Flipped Classroom Methodology in a First-Year Undergraduate Music Research Methods Course
}

\author{
Carolyn Doi (D) \\ University Library, University of Saskatchewan, Saskatchewan, Canada
}

\begin{abstract}
Online learning environments and teaching tools are becoming increasingly present on University campuses and continue to impact the way information literacy instruction is delivered. The flipped classroom is a methodology that allows students to access lecture content before class as homework, leaving room during class time for higher level cognitive activities and assessments. This article discusses a program review of a firstyear undergraduate music library research methods course. A pre- and posttest survey was administered to collect students' perceptions of the methodology as well as information literacy skill development.
\end{abstract}

\section{ARTICLE HISTORY}

Received 15 February 2016

Accepted 15 March 2016

\section{KEYWORDS}

information literacy flipped classroom methodology; academic libraries

\section{Introduction}

In 2012 the Music Department at the University of Saskatchewan requested the development of a new research methods course for all undergraduate music students titled MUS 180: Introduction to Library Research Methods. The course is designed and delivered by the music librarian and aims to introduce students to basic music research sources and strategies, allowing them to better navigate both print and online resources in order to enhance their skills as musicians and scholars. In the context of a programmatic approach to library instruction, MUS 180 ensures that all students receive a consistent introduction to information literacy concepts during their time in the music program. Students are encouraged to take MUS 180 in the first year of study so that later information literacy instruction can build on the learning outcomes throughout the program of study.

The course is offered in a blended learning environment, through asynchronous online instructional elements and face-to-face synchronous classes. The flipped classroom was chosen as a methodology for its flexibility, responsiveness, and effectiveness for information literacy instruction.

This paper will introduce the flipped classroom methodology and its application for use in information literacy instruction. Elements of the course

CONTACT Carolyn Doi carolyn.doi@usask.ca $\Theta$ University Library, University of Saskatchewan, Saskatchewan, Canada S7N 0X1.

Color versions of one or more of the figures in the article can be found online at www.tandfonline.com/WMUS. 
design, video creation process, and assessment activities are reported. Results from a pre- and posttest survey to assess student learning and preferences with the teaching methodology are included.

\section{Literature review}

The flipped or "inverted" classroom methodology has grown in popularity within postsecondary education. ${ }^{1}$ It allows students to acquire understanding of the basic concepts of the course material before class, and class time is then spent building on these concepts and applying knowledge through experiential learning. This flips the traditional lecture based classroom experience upside down, propelling students to reach a more advanced stage of learning within class time. The Flipped Learning Network describes this method as a "pedagogical approach in which direct instruction moves from the group learning space to the individual learning space, and the resulting group space is transformed into a dynamic, interactive learning environment where the educator guides students as they apply concepts and engage creatively in the subject matter." It is this opportunity to "apply concepts and engage" with the subject matter that makes the flipped classroom so appealing for instructors, who are ordinarily faced with limited time in which to introduce the concepts under consideration.

\section{History of the flipped classroom literature}

The flipped classroom methodology first appears in the literature in a 2009 article by Bergman and Sams, which describes the use of prerecorded video lectures to deliver instructional content before class to high school science students. ${ }^{3}$ This arrangement "proved to be an effective way for absent students to catch up, for struggling students to review a lesson, and for... instructors to have high-quality lessons available in [their] absence." Meanwhile, class time was "reserved exclusively for lab activities, demonstrations, one-to-one assistance, and small group tutoring." ${ }^{4}$ Although initially implemented in a high school classroom, the flipped methodology has since made its way into postsecondary institutions, appearing for the first time in the literature in $2012,{ }^{5}$ primarily referring to case studies in STEM classes. ${ }^{6}$ In 2013 the methodology began to make its way into the information literacy literature, first with Johnson's article, which mentions the possible use of the flipped classroom in school libraries, ${ }^{7}$ and subsequently with Datig and Ruswick's article "Four Quick Flips," which addresses the use of the flipped classroom in college campus library instruction for both one-shot and course length library instruction. ${ }^{8}$ The use of the flipped classroom in university music classes has appeared in several articles, documented for the first time 
in 2013. ${ }^{9}$ At the time of writing this article, there are no examples in the literature of the use of the flipped classroom for music library instruction.

\section{Online learning and online instruction}

Popularity of the flipped classroom has been aided by two corresponding changes in the educational landscape: the availability of freely available online learning resources and development of online learning environments. When MIT announced its Open Courseware initiative in 2001 the educational landscape changed significantly, as content from 50 courses was made freely available to the public, the first initiative of its kind. ${ }^{10}$ The Open Learning Initiative from Carnegie Mellon University was launched soon after in 2002, ${ }^{11}$ and in 2006 the Khan Academy was founded as a not-forprofit with the aim to give people free access to instructional content on any subject including "practice exercises, instructional videos, and a personalized learning dashboard that empower learners to study at their own pace in and outside of the classroom." ${ }^{\prime 2}$ Since then, universities have also begun to address the need for online instruction through MOOCs and online courseware initiatives. The development of these online learning initiatives and tools have paved the way for flipped classrooms to flourish in academic learning environments.

\section{Effectiveness of flipped classroom methodology}

Findings in the literature report various outcomes related to the success of the flipped classroom for student learning and engagement. A 2011 study compared student outcomes for two large sections (about 270 students each) of an undergraduate physics course at the University of British Columbia. The control section was taught as a traditional lecture with a recitation, labs, and homework outside of class. In the experimental section, students spent class time discussing pre-assigned readings and solving problems while receiving formative feedback from the instructor and peers. The researchers found that students in the experimental group attended class more regularly, were more engaged, and achieved dramatically higher test results than the control. ${ }^{13}$

In cases reporting on the flipped classroom and one-shot library instruction there are mixed results as to the efficacy and impact of the methodology. Arnold-Garza's article on implementation in a one-shot session reports inconclusive results as to whether the methodology makes for improved instruction sessions. ${ }^{14}$ Wilcox's article "Information Literacy and the Flipped Classroom," presents the results of a comparison of one-shot sessions and finds no difference in scores between two groups on pre- and posttest analysis, though survey result show the majority of students preferred the 
flipped approach. ${ }^{15}$ Datig and Ruswick's article "Four Quick Flips" looked at the flipped classroom in both one-shot sessions and course-integrated sessions. On key information literacy activities students self-reported higher learning in flipped classroom sessions, though no formal study was conducted. ${ }^{16}$

For course-length implementation of the flipped classroom in library instruction, findings report more conclusive evidence that the methodology has a positive impact on student learning and enjoyment. Rivera reported findings in a comparison of methodologies for a Library Workshop Competency course. In this article, pre- and posttest results found that students who participated in the flipped classroom experienced higher increases in posttest results. ${ }^{17}$

Examples from the literature find that the flipped classroom methodology is particularly appropriate for addressing aspects of creativity and hands on learning in music instruction. ${ }^{18}$ Duker notes that the flipped methodology addresses the "perennial problems of core music theory: the need to cover wide-ranging content and develop depth of skill... empowering students to take charge of their own musical growth and connect(ing) their study of theory to a variety of other musical activities." ${ }^{19}$ Grant comments that "the flipped music classroom holds far greater potential than traditional lecture formats to foster authentic and creative student learning activities, for example by incorporating practice- and performance-based learning tasks." 20 Although there are no examples of the flipped classroom for music information literacy instruction in the scholarly literature, examples from similar case studies suggest that application in this area could be successful.

\section{Theoretical framework}

The flipped teaching methodology is situated within a constructivist theoretical framework. Constructivist learning environments are learner-centered with the instructor acting as a facilitator of the learning process. Learning is embedded within realistic and relevant contexts, and acts as a social experience done in dialogue and collaboration. ${ }^{21}$

Application of the flipped classroom methodology is tied closely to the constructivist framework, in particular by finding ways to facilitate the experiential learning process and allowing for more flexibility in the classroom. The Flipped Learning Network identifies four pillars of flipped teaching: a flexible learning environment that "allows for a variety of learning modes," a unique learning culture that "shifts instruction to a learner-centered approach, where in-class time is dedicated to exploring topics in greater depth," intentional content that helps students to "develop conceptual understanding, as well as procedural fluency," and the presence of a professional educator who provides students with "feedback relevant in the moment, and assessing their work." ${ }^{2}$ 
Meanwhile, Brame identifies four key elements that move the implementation of the flipped classroom beyond the initial step of presenting an instructional video. Brame's model states that in order to successfully implement the flipped classroom methodology, the following elements must be included $^{23}$ :

(1) students gain first exposure prior to class through any variety of media from simple textbook readings to lecture videos to podcasts or screencasts

(2) the instructor provides incentive for students to prepare for class by pairing first exposure material with online quizzes, worksheets, short writing assignments

(3) the instructor provides a way to assess students' understanding with a preclass quiz, preclass writing or worksheets in order to help students to clarify their thoughts on the subject matter

(4) the instructor provides in-class activities that focus on higher level cognitive activities, building on the information they've reviewed before class

Essentially, the flipped classroom methodology allows the student to move beyond basic cognitive processes in order to apply learning at a higher level. When applying Bloom's Revised Taxonomy to the flipped classroom, the instructor should aim to have students achieve the lower levels of cognitive work before class (remember, understand) and higher levels during class (apply, analyze, evaluate, create). ${ }^{24}$ The instructor is available to facilitate and answer questions where students are likely to encounter greater challenges, at the higher level of cognition. Applied correctly, the flipped methodology has the potential to extend students' learning beyond what has traditionally been possible in information literacy instruction.

\section{Background}

The University of Saskatchewan is a public research university located in Saskatchewan, Canada. The Department of Music falls within the College of Arts and Science and is located in the College of Education, primarily offering undergraduate programs in music performance and music education. There are approximately 100 FTE undergraduate students enrolled in the music programs, with a complement of nine full-time faculty members and twenty-two sessional instructors.

All students in the four-year undergraduate music program are expected to prepare and present a year-end recital program. In 2012 the Department introduced optional program note requirements for third year students and required program note requirements for fourth-year students. To facilitate 
understanding of the assignment and associated research requirements, the Department established a course in music research methods at the same time the program notes requirements were implemented, recruiting the music librarian to design and deliver the course. As a required course for all music undergraduate students, MUS 180 is intended to introduce basic research skills appropriate for students in the first year of study, to allow for greater facility with navigation and evaluation of library collections and online music resources, while also addressing the basics of citing and writing about music.

In the late 2012 the Gwenna Moss Centre for Teaching Excellence (GMCTE) at the University of Saskatchewan awarded the music librarian a Curriculum Innovation Grant to help with the design of the course syllabus and teaching methodology. Based on consultation with the GMCTE, the course was designed using the flipped classroom methodology in order to develop a learning environment that would be engaging and support student learning. MUS 180 allows students to get comfortable using the library early on and introduces some of the basic research skills that will be crucial in many of the required first- and second-year assignments. Since 2012, the course has been offered four times: fall 2013, fall 2014, fall 2015, and winter 2016. The course is delivered over the course of seven weeks, with one 50minute class per week. Class size is limited to 15 participants.

\section{Course design}

The learning objectives MUS 180 were based on the Association of College and Research Libraries (ACRL) Information Literacy Competency Standards for Undergraduate Education and the Music Library Association Information Literacy Instructional Objectives for Undergraduate Music Students, ${ }^{25,26}$ both of which outline specific standards and performance indicators by which the students learning can be measured. The course syllabus outlines learning objectives and aligns them with weekly modules, video viewing and readings. (See Appendix 1) As part of the course design, five videos were created by the course instructor to support the specific learning objectives and outcomes of the course. Assigned video content came from both existing instructional videos and videos made by the course instructor for the class. It was particularly challenging to find instructional videos on topics related to information literacy for music students, so custom videos were designed for aspects of the class that related specifically to music research (music dictionaries, written sources in music, searching for musical scores, formats and editions of musical scores, and sound recordings). ${ }^{27}$ Where videos on general information literacy topics were appropriate and available, videos from other institutions were used (writing an annotated bibliography, why and when to cite sources, Chicago style basics). 
Online components of the course were presented using Blackboard, the Content Management System (CMS) used in all university courses. Cynthia Brame's four elements in the article "Flipping the Classroom" was used as a guide to structuring the organization of the instructional content, so that it might best meet learning needs. ${ }^{28}$

\section{Students gain first exposure prior to class}

Lecture content was presented the week before the class met in person in the form of required viewing of instructional videos, accompanied by supplementary reading. The instructional videos were made available through the CMS and students were also provided with a link to the video on YouTube.

\section{Provide incentive for students to prepare for class and provide a way to assess student's understanding}

Simply providing access to instructional video online before class is not enough to ensure comprehension of instructional content. Tucker reminds us that "it's not the instructional videos on their own, but how they are integrated into an overall approach, that makes the difference." 29 In order to better integrate the learning from the preclass videos and readings, to test for comprehension and encourage students to actively tune-in to the video content, in-class quizzes were administered by the instructor each week during the MUS 180 course. The quizzes were graded in class, so students could see immediately where they had understood the content, or where there was a gap in their comprehension. Frequently, an in-class discussion of the content followed the quiz, so gaps in understanding could be discussed as a group.

\section{Provide in-class activities that focus on higher level cognitive activities}

Following assessment, each class proceeded with a short lecture, building on the content presented in the video. Following this, a portion of each class was devoted to a hands-on learning activity, intended to further understanding of the theoretical content. The activities were intended to give the student a chance to put theoretical knowledge into practice by working with real-life examples. In-class activities included searching for scores in complete works editions using the Grove Dictionary of Music, critically evaluating sound recordings and liner notes, comparing score editions, and analyzing music reference sources. While students engaged with these activities, the instructor was available to answer questions and facilitate the process. 


\section{Designing instructional videos}

MUS 180 used a combination of instructional videos and supplemental readings to introduce foundational concepts to students. Even though any type of media may be assigned as preclass homework, much of the reviewed literature focusses on the use of instructional video as the starting point for a flipped classroom.

Advice on best practices in designing video lecture videos for the flipped classroom in higher education was discussed in consultation with the Instructional Designer. The Gwenna Moss Centre for Teaching Excellence has created a series of instructional videos for university faculty who are using the flipped classroom methodology on the process of creating lecture videos and the concepts behind the methodology. ${ }^{30}$ The article "Best Practices for Online Video Tutorials in Academic Libraries" also served as a guide to outlining general best practices for video design, including specific advice on pacing, length, content and look and feel, though some of the recommendations for generic self-serve video tutorials do not apply to the flipped classroom. ${ }^{31}$ The most noticeable difference between self-serve videos and flipped classroom video lectures is the length of the videos. Although Bowles-Terry recommends breaking video tutorials into small segments of 30 seconds to 1.5 minutes, the recommended length of flipped classroom video lectures tends to be 1.5 minutes per grade level in a K-12 setting. ${ }^{32}$ In higher education classrooms, this means videos will likely be over 10 minutes.

Documenting the lectures in video format ultimately frees up class time for hands-on activities, giving students a chance to try out concepts for themselves. Having access to them gives students the opportunity to revisit sections of the video that were unclear or return to content later in the semester. The same videos can also be used in following iterations of the course, though they do need to be updated periodically as content goes out of date. An additional and unexpected benefit of creating the videos was they were subsequently used to train library reference staff on key concepts of the music research process.

While the process for creating the videos was time consuming ( 5 hours per video/approximately 25 hours total), the benefit of creating such learning tools is that they can be reused once they are made available. Creating instructional videos for library instruction needs to be carefully planned and given adequate time to work successfully. In this case, the time needed to edit the videos took longer than anticipated. When developing videos in the future more time should be given to plan and edit the content.

The process followed while creating each MUS 180 video lecture is outlined in the steps below, followed by an estimation of the time spent completing each task, based on development of a ten-minute video: 
(1) Develop the lecture content and write a script (2 hours)

(2) Create an outline for the video, mapping out images, screen shots, live demos or power point slides to accompany the script. Use Snagit10 software to capture screen shots and edit images to be used in the video (1 hour)

(3) Record the video and audio using Camtasia software (30 minutes)

(4) Import video to Camtasia software. Select best 'takes' and cut content to ensure clean and quick transitions (1 hour)

(5) Add special effects, captions, highlighting, callouts, etc. using Camtasia software (30 minutes)

(6) Export video to a compatible and upload video to YouTube (30 minutes)

(7) Add YouTube annotations and timings in video description (15 minutes)

(8) Embed video in the Blackboard CMS course module (5 minutes)

Using YouTube to host video content ensured that content would be accessible on a variety of devices (PC, Mac, mobile or desktop access). YouTube also offers a number of editorial features that make it possible to enhance video content, providing several useful navigation and accessibility features. The Annotations feature allows the administrator to add clickable links, text boxes and navigation tools to the video. This acts as a kind of referencing system, providing a link that can be opened in a new window, particularly useful when referring to online resources. ${ }^{33}$ Another useful feature of the YouTube platform is close captioning, which provide an option to make the video content more accessible to users with hearing impairments. Finally, YouTube has added the Cards feature, which allows the creator to provide a destination URL, customized image, title and accompanying text. ${ }^{34}$ The cards appear as a small information icon in the upper corner of the video, which can be clicked at any time to provide a full view of the cards available. Cards can be used for navigation purposes, allowing the viewer to easily find related videos and allowing the administrator to access analytics data.

\section{Assessment}

Students enrolled in MUS 180 participated in several assessments including a final assignment, in-class quizzes and a pre- and posttest. The final assignment for the course was an annotated bibliography, which required students to choose and annotate representative sources of information on a selected piece of music. The sources of information were selected to represent a variety of formats (musical score, sound recording, liner notes, journal article, book, encyclopaedia entry, musical text, or libretto) that are 
commonly used for music research. The assignment made up $50 \%$ of the final grade for the class, and students were also evaluated on attendance and participation in the class. (See Appendix 2)

Pre- and posttest surveys were administered to students enrolled in the course, and included questions addressing student satisfaction with course delivery methods as well as comprehension of key music information literacy skills (identifying scholarly formats, evaluation of various formats for music research, citation practices). Survey results presented here are from pre- and posttests administered in 2014. The survey was developed by the author and distributed in print format during class time. Response rate was $100 \%$ (9 total).

\section{Results}

The survey tool used to measure learning and class enjoyment contained 1 question concerning comfort with library research, 3 questions concerning the teaching methodology and delivery, and 9 questions concerning information literacy skills. Pre- and posttest results were compared using a paired sample $t$-test. See Appendix 3 for all survey questions.

Findings from the survey found that student's confidence with music library research increased by the end of the class. When asked to rank comfort with music library research on a Likert-type scale of 1-7 (1 being a very low confidence level and 7 being a very high research level), student responses rose from an average of 3.97 (56.7\%) before the class started to 5.17 (73.9\%) after the class had ended.

Preferred methods of receiving learning materials during the course changed. When asked to select the preferred method of learning course content using a multiple choice question, students identified lecture and hands-on activities as preferred methods initially (representing a total of $91 \%$ of the total responses), while preclass reading/video viewing ranked much lower as a preferred method of learning. In the posttest results preferences for the three methods was evenly distributed. Preference for preclass reading/video viewing as a method of learning course content increased from $9 \%$ before the class started to $31.25 \%$ after the class had ended. (See Figure 1)

Student perceptions of which instructional methods best facilitate understanding of the course content did not represent a significant change in pre- and posttest results. When asked in a multiple choice question to select the instructional method that best facilitates understanding of course content, the majority of students (40\%) selected hands-on activities in the pretest, which fell to $30 \%$ in the posttest. Group discussion was selected as the best instructional method to facilitate understanding of the course content by $40 \%$ of respondents in the posttest, up $10 \%$ from pretest results. (See Figure 2) 


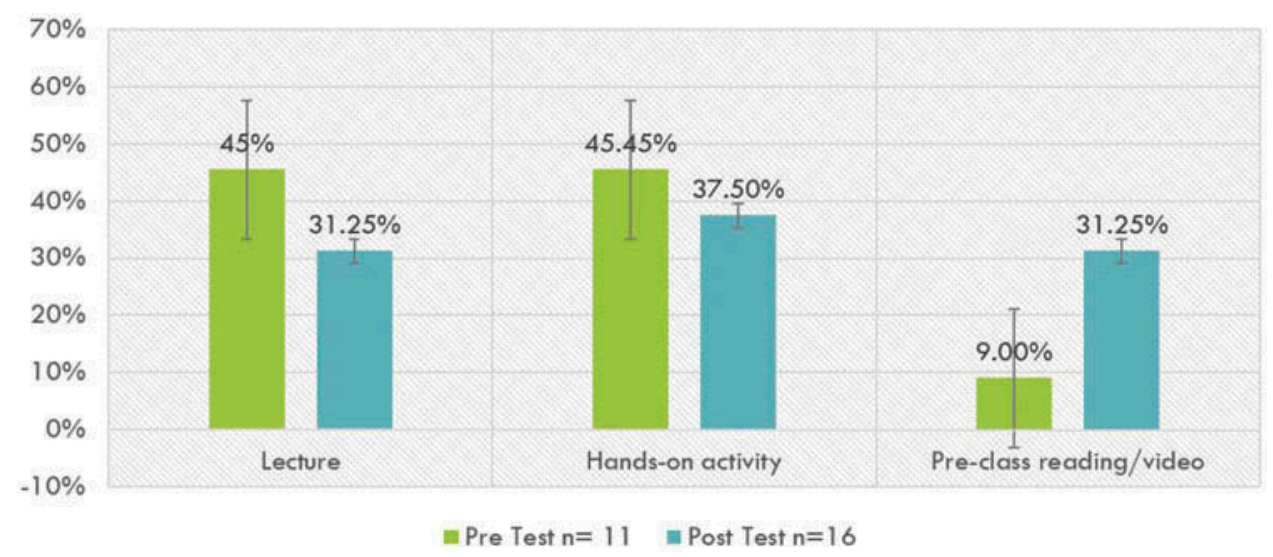

Figure 1. Preferred methods of receiving course content.

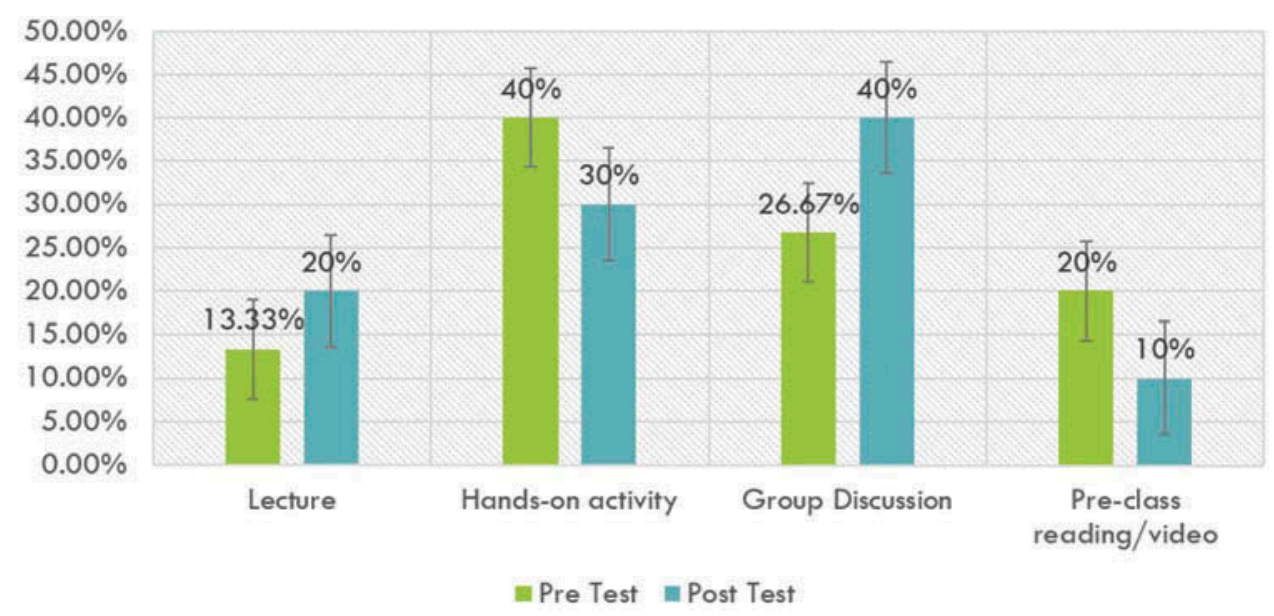

Figure 2. Most effective delivery method for facilitating understanding of course content, perceived.

\section{Discussion}

Although students' understanding of the information literacy skills questions improved in the posttest results, it is not possible to link the flipped teaching methodology with these results as there was no control group. It is interesting to note that both hands-on activities and in-class discussions were ranked most highly in pre- and posttest survey results as the best way to facilitate learning, also being the activities which were used to facilitate higher-level cognitive engagement with learning concepts.

It is noted that the students' preference for receiving course content through the instructional videos increased after completion of the course, though the impression of the videos as the most effective delivery method for facilitating understanding of course content fell. This may be due in part to 
the use of the instruction videos for delivering the foundation concepts of the learning objectives for the course, and it is through the use of in-class activities and discussions to achieve higher levels of understanding are achieved. To have a full understanding of the course content, students likely benefit most from a combination of these approaches.

Although the survey reports on students' engagement with the course content and a basic summary of skills learned during the course, the assessment of the final annotated bibliography assignment provided a more indepth look at student mastery of higher level cognitive learning such as the ability to apply learning in a real-life scenario, analyze information, evaluate information sources, and create new information based on the sources analyzed. Use of a rubric in conjunction with the assignment helped to evaluate the level of understanding at an individual level and provided a reference from which to provide meaningful feedback.

In reflecting on the success of the flipped classroom in a music research methods course, much of the responsibility for success lies with the instructor's ability to move beyond the instructional video and engage with students through meaningful feedback, listening and in-class exploration of the content. Students may not be habituated to the organization of the course, so the instructor must introduce the expectations and organization of the class as soon as possible. Assessing the levels of understanding within the room and discussing how individual experience may contribute to the overall classroom experience are key to making room for open dialogue. The instructor must establish the classroom as a safe space where exploration, questioning and even failure is acceptable, as all lead to a greater understanding of the course content.

Allowing students to access the video lectures before class provides an opportunity to learn at an appropriate pace and review content when necessary. When content is presented in digestible segments and organized into clear topical divisions it is easier to navigate and search for future reference. Instructors must take time to consider both the content of the video, and design principles. Working with an instructional designer may help with this process.

The flipped classroom presents certain challenges for both students and instructors, because it requires more active participation in the learning process by both parties. Still, implementation of quick in-class assessments will allow the instructor to quickly determine the levels of student comprehension and to adjust classroom activities accordingly. Implementation of the flipped classroom is a timely process to begin with, but has great potential to engage learners and make music information literacy instruction more applicable to real-life scenarios. 


\section{Limitations and future directions}

This research reveals some limitations within the survey design and reported data. The validity of the survey results are limited due to the small sample size. As assessment data is collected in subsequent iterations of the course, more meaningful or rigorous conclusions may be drawn. With the opportunity to revise the survey in future years, the instructor plans to incorporate more open ended questions into the design, so that students can report both on how much they enjoyed the method of instructional delivery, but also why they felt this way. Additional questions specifically about the design of the videos themselves would also broaden the picture of the efficacy of the flipped teaching methodology for music library instruction.

Although the responses to the in-class assessments were not collected for this research, subsequent years have seen the implementation of online quizzes, which do capture an impression of student's grasp of the concepts immediately after completing the video viewing requirements. As an avenue for further research, a presentation of this data would help to assess the impact of video viewing on initial comprehension and learning in the MUS 180 class.

\section{Conclusions}

Although the flipped classroom has origins in K-12 and later in university STEM courses, there is also evidence to suggest that it is effective for information literacy instruction, particularly where a full-length course is offered. Presenting the fundamental information before class is ideal for library skills instruction as information on search strategies, database layout and other preliminary information does not necessarily make for engaging classroom content and often needs to be reiterated when students actually try to apply the search strategies themselves.

Within the music classroom, the flipped classroom methodology can also be used to good effect. Music students are accustomed to engaging with information creatively and they are generally open to participating fully in classroom activities. As Grant mentions, the flipped classroom is a prime way to "foster authentic and creative student learning activities, for example by incorporating practice- and performance-based learning tasks. More than the traditional lecture format, it can engage students in real-life problem solving in areas relevant to their future careers as musicians, and develop the entrepreneurial skills that are increasingly needed to build a successful and sustainable career in the arts. ${ }^{\prime 35}$ Likewise, in the area of research skill development, the purpose is to prepare students to solve real-life research problems. Skill development in areas of search strategies and source evaluation will become an increasingly important area of knowledge throughout 
postsecondary studies, while critical thinking and evaluation skills are lifelong learning goals that move far beyond the university environment.

Although students initially indicated a lower preference for instructional videos as a method of receiving course content, preference for the format increased after completing the course. Based on the survey results and final assignment assessments, students were able to demonstrate a high level of engagement with information sources, to demonstrate critical thinking and evaluation skills that will benefit them both as scholars and musicians.

As MUS 180 continues to grow, moving assessment activities online will allow for more systematic and immediate evaluation of the student's retention of the video lecture content, making it easier to track each students' progress. The design of the course will continue to develop especially in light ACRL's newly developed Framework for Information Literacy for Higher Education and recently established Undergraduate Learning Objectives for Information Literacy at the University Library, University of Saskatchewan. ${ }^{36}$ Both documents bring a new perspective to undergraduate information literacy instruction. As information literacy instruction continues to evolve alongside online teaching tools, online learning environments, and organizational frameworks, the flipped classroom methodology provides an useful framework with the potential to significantly enhance student learning and engagement.

\section{Notes}

1. Philip Duker, Anna Gawboy, Bryn Hughes, and Kris P. Shaffer, "Hacking the Music Theory Classroom: Standards-Based Grading, Just-in-Time Teaching, and the Inverted Class," Music Theory Online 21, no. 1 (2015): 23.

2. Flipped Learning Network, "Definition of Flipped Learning," Flipped Learning Network, 2014, http://flippedlearning.org//site/Default.aspx?PageID=92.

3. Jonathan Bergmann and Aaron Sams, "Remixing Chemistry Class," Learning and Leading with Technology 36, no. 4 (2008): 24-27.

4. Ibid., 22.

5. Simon Bates and Ross Galloway, "The Inverted Classroom in a Large Enrolment Introductory Physics Course: A Case Study,” 2012, 1-9, https://www.cs.auckland.ac.nz/ courses/compsci747s2c/lectures/paul/Simon_Bates_Ross_Galloway.pdf.; Dan Berrett, "How Flipping the Classroom Can Improve the Traditional Lecture," The Chronicle of Higher Education 12 (2012): 1-14.; Zhang Jinlei, Wang Ying, and Zhang Baohui, "Introducing a New Teaching Model: Flipped Classroom," Journal of Distance Education 4 (2012): 46-51.; Glen Bull, Bill Ferster, and Willy Kjellstrom, "Inventing the Flipped Classroom," Learning \& Leading with Technology 40, no. 1 (2012): 10.

6. Ilka Datig and Claire Ruswick, "Four Quick Flips: Activities for the Information Literacy Classroom," College \& Research Libraries News 74, no. 5 (2013): 249.

7. Doug Johnson, “The Online Librarian," Library Media Connection 32, no. 3 (2013): 98.

8. Datig and Ruswick, "Four Quick Flips."

9. Catherine Grant, "First Inversion: A Rationale for Implementing the "Flipped Approach' in Tertiary Music Courses," Australian Journal of Music Education 1 (2013): 3-12; Trevor De Clercq, "Towards a Flipped Aural Skills Classroom: 
Harnessing Recording Technology for Performance-Based Homework," In Engaging Students: Essays in Music Pedagogy, 2013. http://flipcamp.org/engagingstudents/ deClercq.html (accessed February 16, 2016); Philip Duker, Anna Gawboy, Bryn Hughes, and Kris P. Shaffer, "Hacking the Music Theory Classroom: StandardsBased Grading, Just-in-Time Teaching, and the Inverted Class," Music Theory Online 21, no. 1 (2015): 23.

10. "Our History," MIT OpenCourseWare, http://ocw.mit.edu/about/our-history/ (accessed November 8, 2015).

11. "Learn More About OLI: Open Learning Initiative," Carnegie Melon University, http:// oli.cmu.edu/get-to-know-oli/learn-more-about-oli/ (accessed February 16, 2016).

12. "Khan Academy," Khan Academy, http://www.khanacademy.org (accessed November 8, 2015).

13. Louis Deslauriers, Ellen Schelew, and Carl Wieman, "Improved Learning in a LargeEnrollment Physics Class," Science 332, no. 6031 (2011): 862-64, doi:10.1126/ science. 1201783.

14. Sara Arnold-Garza. "The Flipped Classroom: Assessing an Innovative Teaching Model for Effective and Engaging Library Instruction," College \& Research Libraries News 75, no. 1 (2014): 10-13.

15. Andrea Wilcox Brooks, "Information Literacy and the Flipped Classroom," Communications in Information Literacy 8, no. 2 (2014): 225-35.

16. Datig and Ruswick, "Four Quick Flips."

17. Eduardo Rivera, "Using the Flipped Classroom Model in Your Library Instruction Course," The Reference Librarian 56, no. 1 (January 2, 2015): 41, doi:10.1080/ 02763877.2015.977671.

18. Duker et al., "Hacking the Music Theory Classroom."; Grant, "First Inversion."

19. Duker et al., "Hacking the Music Theory Classroom," 6.

20. Grant, "First Inversion," 6.

21. Brent Gayle Wilson, Constructivist Learning Environments: Case Studies in Instructional Design, Englewood Cliffs, Educational Technology Publications, 1996.

22. Flipped Learning Network. "Definition of Flipped Learning." Flipped Learning Network, 2014, http://www.flippedlearning.org/definition (accessed February 16, 2016).

23. Cynthia J. Brame, "Flipping the Classroom," Vanderbilt University, Center for Teaching, 2013, http://cft.vanderbilt.edu/guides-sub-pages/flipping-the-classroom/ (accessed February 16, 2016).

24. David R. Krathwohl, “A Revision of Bloom's Taxonomy: An Overview," Theory Into Practice 41, no. 4 (2002): 212-18, doi:10.1207/s15430421tip4104_2.

25. "Information Literacy Competency Standards for Higher Education: Association of College \& Research Libraries (ACRL)," http://www.ala.org/acrl/standards/information literacycompetency (accessed February 15, 2016).

26. Laurie J. Sampsel and Paul Cary, "Information Literacy Instructional Objectives for Undergraduate Music Students," Notes 62, no. 3 (2006): 663-79.

27. C. Doi, "Music Dictionaries," YouTube video, 9:43, posted by "Carolyn Doi," https:// youtu.be/tVRV7YNq20E (accessed September 29, 2014); C. Doi, "Music Scores: Formats and Editions," YouTube video, 10:08, posted by "Carolyn Doi," https:// youtu.be/wKcGIEFdH00 (accessed October 6, 2014); C. Doi, "Music Scores: Searching," YouTube video, 6:31, posted by "Carolyn Doi," https://youtu.be/ XmcJWea9bbA (accessed October 7, 2014); C. Doi, "Music Recordings," YouTube video, 8:57, posted by "Carolyn Doi," https://youtu.be/a5MJDhcWP80 (accessed October 20, 2014); C. Doi, "Written Sources," YouTube video, 11:46, posted by "Carolyn Doi," https://youtu.be/1TDncqBQg5s (accessed October 27, 2014). 
28. Brame, "Flipping the Classroom."

29. Bill Tucker, "The Flipped Classroom: Online Instruction at Home Frees Class Time for Learning," Education Next, 2012, 82-83.

30. "Creating a Lecture Video using Screencast-o-matic," YouTube video, 5:08, posted by "GMCTE UofS," https://youtu.be/EUBetZmNUQ0 (accessed December 4, 2012); "Flipped Teaching Approach to Case-Based Learning," YouTube video, 5:19, posted by "GMCTE UofS," https://youtu.be/w6Ifuc9lAH8.(accessed December 4, 2012).

31. Melissa Bowles-Terry, Merinda K. Hensley, and Lisa J. Hinchliffe, "Best Practices for Online Video Tutorials in Academic Libraries: A Study of Student Preferences and Understanding," Communications in Information Literacy 4, no.1: 17-18, http://hdl. handle.net/2142/18671.

32. David Raths. "9 Video Tips for a Better Flipped Classroom," Transforming Education Through Technology Journal (2013): 3, https://thejournal.com/Articles/2013/11/18/9Video-Tips-for-a-Better-Flipped-Classroom.aspx?Page $=3$.

33. "Create and Edit Annotations," YouTube Help, https://support.google.com/youtube/ answer/92710?hl=en (accessed March 10, 2014).

34. "Add Cards to Videos," YouTube Help, https://support.google.com/youtube/answer/ 6140493?hl=en (accessed March 10, 2014).

35. Grant, "First Inversion," 6.

36. Association of College and Research Libraries, "Framework for Information Literacy for Higher Education," Association of College and Research Libraries, http://www.ala. org/acrl/standards/ilframework (accessed February 2, 2015); "Angie Gerrard, Carolyn Doi, Vicky Duncan, David Francis, and Li Zhang, "Program for Information Literacy Instruction at the University Library," (internal report) University Library, University of Saskatchewan, December 23, 2015.

\section{ORCID}

Carolyn Doi (i) http://orcid.org/0000-0002-4772-3308 


\section{Appendix 1. Course learning objectives and learning modules taken from the course syllabus}

Learning objectives:

By the end of the course, students should be able to:

(1) make effective use of the library's services and resources

(2) determine the nature and extent of the information needed by:

(a) exploring general information sources such as music encyclopedias, dictionaries, music histories and composer biographies

(b) identifying a variety of types and formats of potential sources of information including primary, secondary and tertiary sources

(c) identifying the value and differences of potential resources in a variety of formats including books, articles, scholarly, critical and performance editions, sound recordings in various formats; web sites

(d) identifying the purpose and audience of potential resources (popular vs. scholarly, current vs. historical)

(3) access needed information effectively and efficiently by:

(a) selecting efficient and effective approaches for finding scores in collected sets, anthologies

(b) constructing and implementing effectively-designed search strategies

(c) retrieving information online or in person using a variety of methods including search systems and classification schemes

(d) refining the search strategy if necessary by assessing the quantity, quality and relevance of the search results and identifying gaps in the information retrieved

(4) evaluate information and its sources critically by recognizing reliability, validity, accuracy, authority, timeliness and point of view or bias

(5) extract, record and manage the information and its sources by:

(a) understanding the elements and correct syntax of a citation elements about music, musical scores, sound recordings, videos and electronic resources

(b) using an appropriate documentation style consistently to cite musical sources. 
Learning modules

\begin{tabular}{|c|c|c|c|}
\hline Week & Module & Videos and Readings & Assignments \\
\hline Week One & $\begin{array}{l}\text { Pretest assessment. } \\
\text { Introducing library services } \\
\text { and resources. Introduction } \\
\text { to research in music. }\end{array}$ & $\begin{array}{l}\text { Video: "Annotated } \\
\text { Bibliography" by GPCL } \\
\text { Libraries. http://youtu.be/A- } \\
\text { o-AGu4XDM Bayne: "The } \\
\text { Research Process" p. 5-9 }\end{array}$ & $\begin{array}{l}\text { Complete online } \\
\text { assessment tool before } \\
\text { next class (Blackboard) }\end{array}$ \\
\hline Week Two & $\begin{array}{l}\text { Searching and evaluating } \\
\text { general information sources } \\
\text { such as dictionaries and } \\
\text { encyclopaedias. }\end{array}$ & $\begin{array}{l}\text { Video: "Music Dictionaries" } \\
\text { https://youtu.be/ } \\
\text { tVRV7YNq20E Bayne: } \\
\text { "Starting-Point Resources: } \\
\text { Reference Books" p. 13-15 } \\
\text { Bellman: "Reference } \\
\text { Sources" p. } 96\end{array}$ & $\begin{array}{l}\text { Complete online } \\
\text { assessment tool before } \\
\text { next class (Blackboard) }\end{array}$ \\
\hline Week Three & $\begin{array}{l}\text { Finding, evaluating and } \\
\text { using scores including } \\
\text { collected and complete } \\
\text { works editions }\end{array}$ & $\begin{array}{l}\text { Video: "Music Scores: } \\
\text { Formats and Editions" } \\
\text { https://youtu.be/ } \\
\text { wKcGIEFdH00 Video: "Music } \\
\text { Scores: Searching" https:// } \\
\text { youtu.be/XmcJWea9bbA } \\
\text { Bayne: "M: The Music- } \\
\text { Scores and Recordings" p. } \\
\text { 183-93. }\end{array}$ & $\begin{array}{l}\text { Complete online } \\
\text { assessment tool before } \\
\text { next class (Blackboard) } \\
\text { Submit selected work for } \\
\text { final assignment. }\end{array}$ \\
\hline Week Four & $\begin{array}{l}\text { Finding, evaluating and } \\
\text { using recordings, liner } \\
\text { notes, and video }\end{array}$ & $\begin{array}{l}\text { Video: "Music Recordings" } \\
\text { https://youtu.be/ } \\
\text { a5MJDhcWP80 Bellman: } \\
\text { "Recording Liner Notes" p. } \\
\text { 100-2 }\end{array}$ & $\begin{array}{l}\text { Complete online } \\
\text { assessment tool before } \\
\text { next class (Blackboard) }\end{array}$ \\
\hline Week Five & $\begin{array}{l}\text { Finding, evaluating and } \\
\text { using music literature, } \\
\text { articles, and books }\end{array}$ & $\begin{array}{l}\text { Video: "Written Sources" } \\
\text { https://youtu.be/ } \\
\text { 1TDncqBQg5s Bayne: "ML: } \\
\text { Music Literature" p. } \\
\text { 195-207. Bellman: "Books," } \\
\text { "Journal and Magazine } \\
\text { Articles" p. 97-8 }\end{array}$ & $\begin{array}{l}\text { Complete online } \\
\text { assessment tool before } \\
\text { next class (Blackboard) }\end{array}$ \\
\hline \multicolumn{4}{|c|}{ Annotated Bibliography due } \\
\hline Week Six & $\begin{array}{l}\text { Information has value. } \\
\text { Giving credit to the original } \\
\text { ideas of others. Extract, } \\
\text { record, and manage the } \\
\text { information and its sources. }\end{array}$ & $\begin{array}{l}\text { Video: "Citing-How to Cite } \\
\text { in Chicago/Turabian Style: A } \\
\text { Three Minute Tutorial" } \\
\text { https://youtu.be/ } \\
\text { ONdT4Y620nE Video: "Cite } \\
\text { Your Sources: When/Why to } \\
\text { Cite" https://youtu.be/ } \\
\text { ziG9LtljRUU Bellman: "Citing } \\
\text { Your Sources" p. 109-112 }\end{array}$ & $\begin{array}{l}\text { Complete online } \\
\text { assessment before next } \\
\text { class (Blackboard) }\end{array}$ \\
\hline Week Seven & $\begin{array}{l}\text { Introduction to writing } \\
\text { program notes. Review and } \\
\text { feedback on the final } \\
\text { assignment. Posttest } \\
\text { assessment. }\end{array}$ & $\begin{array}{l}\text { Bayne: "Writing Samples: } \\
\text { Program Notes" p. 68-71 } \\
\text { Bellman: "Program and } \\
\text { Liner Notes" p. 56-9 }\end{array}$ & \\
\hline
\end{tabular}




\section{Appendix 2. Annotated bibliography assignment}

Grade percentage: $50 \%$

Assignment guidelines

Imagine you will be writing scholarly program notes about a musical work. You will need to conduct research to find information sources about this work that are accurate, reliable and scholarly wherever possible. Select a piece of music on which you wish to focus your research. If you choose an opera or song cycle, you may wish to choose one aria as opposed to the entire work. For this assignment, you will compile a bibliography that includes at least 10 sources. The bibliography must include the following formats:

1-3 dictionary and/or encyclopedia entries

$1-3$ books

$1-3$ journal articles

1 recording

1 recording liner note

1 score

1 libretto/text (for works based on a text)

Online sources (if none of the above are available or if the source is exceptionally reputablei.e., a composer's personal web site).

If you are unable to locate any of these formats while doing your research, include a note at the end of the assignment, which explains where you looked and why the particular format is not being included in the bibliography. The sources you choose may serve as sources to study the piece (scores and recordings), or serve to illustrate the following points:

biographical information about the composer

Information about the style or affect of the piece

Information about the context in which the piece was written.

Format the bibliography according to the Chicago Manual of Style. Use a citation guide to find examples of proper style: http://libguides.usask.ca/music/citation. Entries in the bibliography should be organized alphabetically. Each citation should be followed by an annotation of approximately 150 words $( \pm 25)$. The annotation should include both a description of the source and assessment of its relevance to the research topic. Points for inclusion:

Description of the source

Format and point of access (online or print).

Special features of the work that are unique or helpful.

Intended audience (scholarly or poplar).

For scores: note the edition and what this may imply for your research. (Is it scholarly, popular, urtext, edited, etc.?)

Possibly compare this item to another similar one in the bibliography. (e.g., two biographies written from different perspectives.)

\section{Assessment of the source}

Usefulness or relevance to your research topic.

Reliability of the source (including currency, credibility of the source, quality of the publication, etc.) 


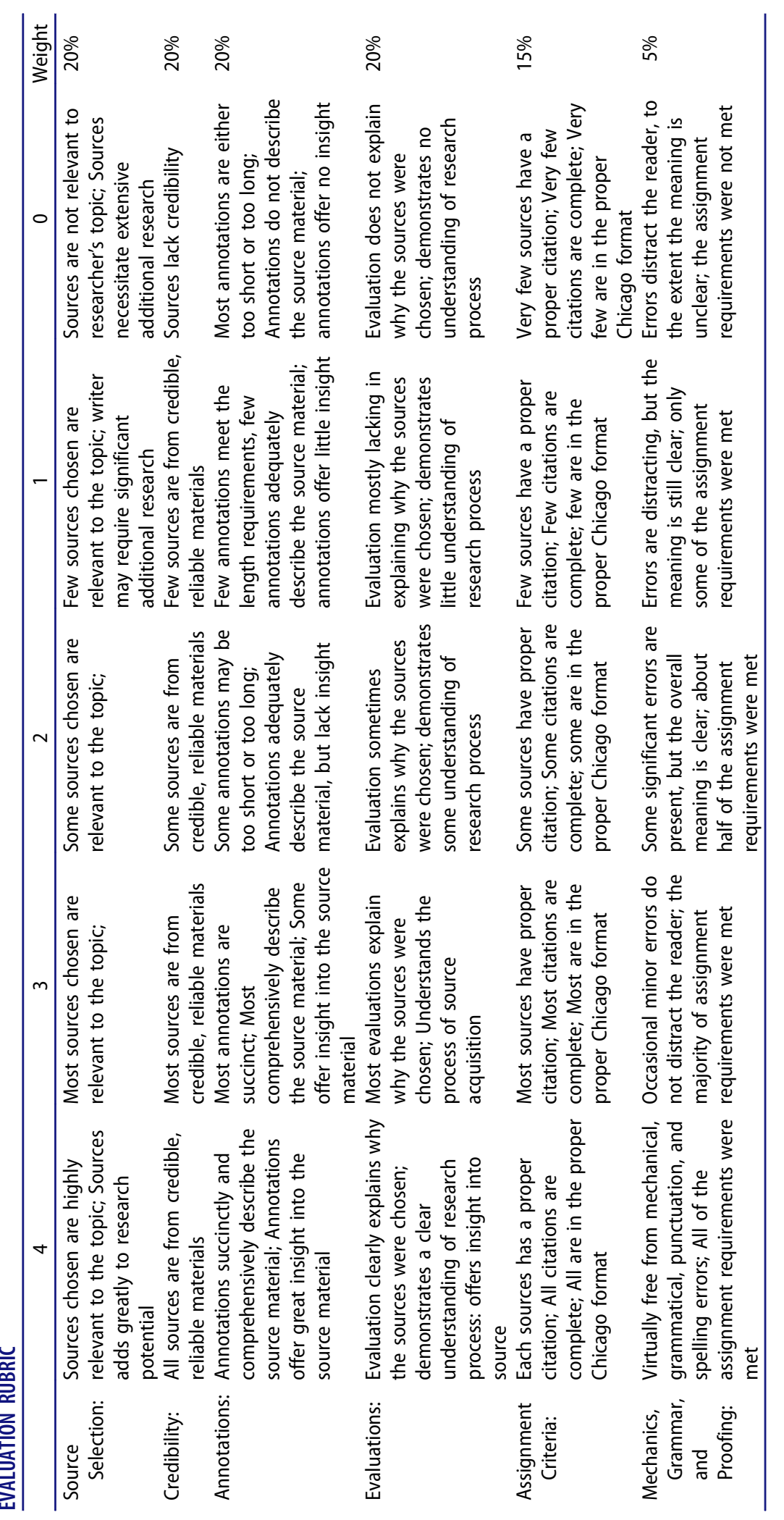




\section{Appendix 3. Pre- and posttest survey questions}

\section{Experience with library research}

What is your confidence level in doing library research and searching?

1 [very low comfort level] -7 [very high-expert researcher]

\section{Course content}

An annotated bibliography is: (pick one)

Always published in a scholarly journal

\begin{tabular}{|l|l|l|l|l|l|l|}
\hline 1 & 2 & 3 & 4 & 5 & 6 & 7 \\
\hline
\end{tabular}

Identifies important sources of information on a topic in content formatting

Offers a summary of the sources

Offers a critical assessment of the materials

$\mathrm{A}$ and $\mathrm{D}$

$\mathrm{B}$ and $\mathrm{C}$

$\mathrm{B}, \mathrm{C}$ and $\mathrm{D}$

"The Grove Dictionary of Music and Musicians" is: (check all that apply)

More like an encyclopedia than a dictionary

Available online and in print

Includes mostly color photographs and diagrams

Available in print only

Useful for getting background information on a topic

Includes bibliographies

Includes works lists for most composers

"The Grove Dictionary of Music and Musicians" can be used to locate pieces in the complete works editions:

$\square$ yes

$\square$ no

$\square$ not sure

Critical, urtext, performing and facsimile editions of scores can be used interchangeably:

$\square$ True

$\square$ False

Critical editions of scores include editorial procedures that distinguish between the composer's notation and editorial additions or changes:

$\square$ True

$\square$ False

Liner notes always contain valuable information useful for scholarly research and writing:

$\square$ Yes

$\square$ No

$\square$ Sometimes

$\square$ Not sure

The "Naxos Music Library" is: (pick one)

A library database

A record label

A place to find source recordings and liner notes

A place to find journal articles

A peer-reviewed article is: (check all that apply)

Read by students at universities before it is published

Approved by an editor before it is published 
Approved by one or more outside readers before it is published

Can appear in a newspaper or magazine

Can appear in a journal

Is likely of better quality than an article that is not peer-reviewed

"The Chicago Manual of Style" includes: (check all that apply)

Guidelines for how to write academic papers

Advice on when to start your paper

Examples of how to cite sources

Examples of how to include sources in a bibliography

Information on how to conduct research

\section{Teaching Methodology}

Do you think the course format (presentation of video lecture beforehand/discussion \& activities during class) facilitates learning of the course content?

Yes

No

Maybe

Not Sure

What is your preferred method of learning course content? (pick one)

Lecture

Hands-on-activity

Preclass reading/video

Combination of the above options

Which one of these methods best facilitates your understanding of the course content? (pick one)

Lecture

Hands-on activity

Group discussion

Preclass reading/video 